\title{
A Comunhão no Regime da Separação de Bens
}

\author{
Alvaro Villaça Azevedo \\ Doutor em Direito e Professor Adjunto \\ de Direito Civil pela USP e Professor \\ Titular de Direito Civil da Faculdade de \\ Direito da Universidade Mackenzie
}

A cogitar-se do regime da separação de bens, tem-se como regra a incomunicabilidade do patrimônio de cada cônjuge, quer anterior, quer posterior, ao casamento.

Aliás, o artigo 276 do Código Civil assenta que o casamento, sob esse regime de separação, faz com que cada cônjuge reste administrador exclusivo de seus bens, podendo alienar os móveis sem a necessidade de outorga do outro consorte, só exigida quanto aos imóveis.

Tenha-se, ainda, neste passo, que uma indagação se faz presente, no tocante aos aqüestos; seriam estes de propriedade separada, de cada cônjuge?

Daí, a ponderação do legislador, no artigo 259 do Código Civil, para responder a essa questão, ao assentar que, mesmo que não seja da comunhão de bens o regime matrimonial, no silêncio do pacto ante-nupcial, ela vigorará no tocante ao que adquirirem os cônjuges na constância de seu casamento.

Que teria querido o legislador? Transformar o regime da separação, afeiçoando-o ao da comunhão parcial, em que se comungam os aqüestos adquiridos a título oneroso?

Parece-nos que a preocupação não foi essa, pois, sendo expresso o contrato pré-nupcial, a estipular o regime separatório, não haverá comunhão.

O que quis, mesmo, o legislador, salvo melhor entendimento, foi premiar o esforço comum dos cônjuges, mais no sentido condominial do que comunheiro.

Os cônjuges que convivem no lar conjugal, passando pelos bons e maus momentos, são sócios nas tristezas e nas alegrias, reclamando tal fato, in genere, que sua sorte patrimonial seja a mesma. 
Restaria, entắo, a dúvida, no tocante ao regime da separaçăo legal, em que os cônjuges não podem escolher a forma patrimonial de seu matrimônio, mas são obrigados a se consorciarem sob esse regime, por imposição da lei. Assim, nos casos previstos no parágrafo único do artigo 258 do Código Civil, esse regime é obrigatório, como por exemplo para os homens com mais de sessenta e para as mulheres com mais de cinqüenta anos, que se casam.

Como visto, o regime da separação de bens ou é convencional ou é legal, nos casos aludidos.

Quando ele vigora por pacto-nupcial, este deve ser expresso em repelir a comunhão dos aqüestos, sob pena de vigorar esta forma de comunicação patrimonial, conforme o invocado artigo 259 do Código Civil. Deve conter-se, nessa avença, desse modo, verdadeira cláusula de incomunicabilidade de bens, para ilidir-se a regra geral da comunicação.

Sob o regime da şeparação de bens obrigatório, mais uma razão, a nosso ver, que vigore a regra da comunicação dos aqüestos, pois a lei, por circunstâncias, que estabelece, rouba aos nubentes a possibilidade de contratarem seu regime matrimonial. Todavia, mesmo sob a separação legal, ou obrigatória, para obviar essa possibilidade de comunicação dos aqüestos, podem os nubentes pré-contratar a incomunicabilidade de seus bens, por força do mesmo artigo 259 .

Bem demonstra o Professor WASHINGTON DE BARROS MONTEIRO (Curso de Direito Civil, Direito de Família, Ed. Saraiva, São Paulo, 19 ed., 1980, págs. 174 e 175) que há duas correntes, uma que admite, e outra que não, a comunicabilidade dos aqüestos no regime obrigatório, legal da separação de bens, explicando que a primeira encontra fundamento no esforço comum dos cônjuges e a segunda no fato se só existir comunicabilidade no silêncio do contrato pré-nupcial. $\mathrm{E}$ aduz o Professor das Arcadas, posicionando-se do seguinte modo: "o primeiro ponto de vista é o mais acertado, em virtude do estabelecimento de verdadeira sociedade de fato, ou comunhão de interesses entre os cônjuges".

Não há razão para que os bens fiquem pertencendo exclusivamente a um deles, desde que representam trabalho e economia de ambos. É a conseqüência que se extrai do artigo 1.176 do Código Civil, referente às sociedades civis e extensiva às sociedades de fato ou comunhão de interesses.

Nesse sentido existe presentemente súmula do Supremo Tribunal Federal $n^{\circ} 377$.

Realmente, o princípio sumulado sob $\mathrm{n}^{\circ} 377$ de nossa Suprema Corte de Justiça, indene de dúvidas, acolhe esse posicionamento doutrinário e jurisprudencial, assentando que "no regime de separação legal de bens comunicam-se os adquiridos na constância do casamento". 
Algumas vozes levantaram-se pela inaplicabilidade do artigo 259 do Código Civil ao regime obrigatório da separação de bens, todavia tão fracas ante a injustiça e ilegitimidade de pensamento que tal posição viu-se veementemente alijada pela melhor jurisprudência, com o surgimento, a final, da aludida súmula 377.

O professor SILVIO RODRIGUES (Direito Civil, Direito de Família, Ed. Saraiva, São Paulo, 8? ed., 1980, vol. VI, págs. 182 e 183 e in Revista dos Tribunais, vol. 246, pág. 36, "Os aqüestos no regime legal da separação de bens, Pesquisa na Jurisprudência"), diante deste quadro jurisprudencial, assertiva que "Tal solução" em seu entender, "fora de qualquer dúvida, se afasta da lei. Mas, como vem atender a um anseio de justiça, que ficaria inalcançado se fosse aplicar friamente o texto legal, merece o mais veemente aplauso."

Ao nosso ver, entendemos que, se o legislador impõe como regime de bens o da separação, não pode contudo retirar, de futuro, a comunicabilidade natural do patrimônio, no sistema da sociedade conjugal. Em toda sociedade, não havendo convenção em contrário, a regra é a da comunicação dos bens entre sócios. Isto, até na sociedade de fato, no concubinato, conforme a súmula 380 de nosso Supremo Tribunal Federal; imagine-se, então, em se tratando de casamento!!!

Assim não ser os concubinos teriam mais direitos do que os casados sob o regime da separação de bens, pois o princípio deste aplica-se àqueles, a não ser no que tange aos bens adquiridos durante a convivência concubinária. Basta esta, entendemos, para que já se admita o condomínio nascido do esforço comum dos concubinos, pois não se uniram eles sob mera sociedade de fato, como João e José, em qualquer empresa mas com o intuito de constituírem sua família; com um atestado societário mais forte, que deve merecer todo o apoio e toda a proteção do Estado, por seus poderes constituídos.

E o que mais se tem sensibilizado, nesse sentido, é o Poder Judiciário, que não vê as aparências, mas os verdadeiros sentimentos humanos; não se vê os formalismos da lei, em matéria familiar, mas a verdadeira norma que o Direito Natural ensina ao homem, desde o dia em que ele nasce: que ele é um ser gregário e necessita viver em família, com ou sem filhos, de direito ou de fato, sob a égide protetiva de um patrimônio conquistado pelos consortes, na sua convivência, com dignidade de tratamento entre os membros dessa célula, com compreensão, respeito e amor.

Essa família que o Estado deve preservar, para que ele seja, cada vez mais, fortalecido, por sentimentos e não por excessos de documentação e formalismos. Aí a grande lição dos romanos, que viam no casamento um verdadeiro fato social, que nasce espontaneamente na sociedade, sem que seja recessária muita regulamentação legal, a não ser para preservar os efeitos da união, o complexo de direitos e de deveres entre os cônjuges existentes e deles com sua prole, e para 
defender a dignidade dos integrantes da família, pessoal e patrimo* nialmente.

Acrescente-se, todavia, que, na sensível sociedade familiar, mesmo na vigência do ante-pactuado regime da mais completa e absoluta separação de bens, podem vir a existir estes, embora em nome de um dos cônjuges, pelo esforço comum do casal.

Aí, então, o Direito de Família há que se curvar, como já foi dito quanto à sociedade concubinária, ao Direito das Coisas e das Obrigações, no plano societário comum.

Pois, a cogitar-se nessa esteira, há verdadeira sociedade de fato, entre os cônjuges, paralelamente a seu regime de bens. Aliás, nesse caso, a matéria como visto, se transporta ao âmbito do direito co-proprietário, em abstração, até, do regime matrimonial eleito.

Os cônjuges, que convivem no lar conjugal, passando pelos bons e maus momentos, são sócios no patrimônio que resultar de seu esforço comum.

Aliás, cogitando desse mister, ensina Sílvio RODRIGUES (Direito Civil, pág. 180) que "O princípio da incomunicabilidade dos aquiestos teve sua rigidez entibiada pela idéia de que, entre os cônjuges, embora casados pelo regime de separação absoluta de bens, se estabelecia uma sociedade de fato, e os bens havidos em comum pertenciam à comunidade. Haveria, decerto, na conjugação de esforços, uma affecttio socitatis e, se permitisse que só um dos esposos recebesse o ganho, facultar-se-ia um enriquecimento indevido.

Como já se fez notar, à citação do entendimento cumulado sob $n^{\circ} 377$ de nossa Colenda Corte Suprema deve ele de aplicar-se, a nosso ver, em qualquer situação para possibilitar a premiação do esforço conjugal comum.

Esse esforço comum leva, necessariamente, à sociedade de fato.

Anote-se, neste passo, a lição do Professor YUSSEF SAID CAHALI (Bens Aqüestos, verbete da Enciclopédia Saraiva do Direito, Ed. Saraiva, São Paulo, 1978, vol. 11, pág. 154), que, sob o mesmo passo de analisar dito princípio sumulado, acolhe: "a solução pretoriana que inspirou a súmula $\mathrm{n}^{\circ} 377$ traz em seu contexto argumentos que se mostram igualmente respeitáveis: se o marido e a mulher se mantiveram sempre unidos e conjugaram esforços para levar a cabo a formação do patrimônio comum, ainda que a cooperação da esposa tenha sido limitada ao trabalho doméstico, tem ela indiscutivelmente o direito, até mesmo natural, de compartilhar daquele complexo de bens; assim, o entendimento consagrado na referida súmula já não procura socorrer-se de qualquer interpretação literal de normas dos arts. 258, parágrafo único e 259 do $\mathrm{CC}$; cuida-se, sim, do reconhecimento do esforço comum dos cônjuges na formação do patrimônio, matéria que foge ao âmbito do direito de família; o esforço comum é, pois o traço que imprime aos aqüestos a força de sua comunicabilidade; 
assim, desde que, por presunção, os bens terão assim provindo de esforços comuns, então ambos deverão pertencer $O$ entendimento sumulado tem sido confortado pela Jurisprudência posterior (RT, 492:242; 464:217; RJTJSP, $17: 145 ; 15: 178) "$.

Portanto, não há como negar que, quanto ao patrimônio pelo esforço comum, quer na relação concubinária, quer na matrimonial, existe verdadeiro condomínio, e em uma sociedade especialíssima em que o respeito ao direito patrimonial decorre do de caráter familiar, com maior razão para que, eventual partilha, não sucumba ao sentimento nobre do amor dos cônjuges que propulsionou, com alento superior e mais forte, o ânimo da construção patrimonial cumum. 